\title{
Measuring portfolio loss using approximation methods
}

\section{Osei Antwi}

Mathematics \& Statistics Department, Accra Polytechnic, Accra, Ghana

\section{Email address:}

oseiantwi@yahoo.co.uk

\section{To cite this article:}

Osei Antwi. Measuring Portfolio Loss Using Approximation Methods. Science Journal of Applied Mathematics and Statistics. Vol. 2, No. 2, 2014, pp. 42-52. doi: 10.11648/j.sjams.20140202.11

\begin{abstract}
One of the approaches to determining and quantifying the credit risk of a loan portfolio is by obtaining the distribution of losses of the portfolio and determining the risk quantities from such distributions. In this paper, we describe the challenges to using this approach and illustrate a practical solution where simulation methods are used to obtain loss distribution for a two obligor portfolio. This is then extended to ten and hundred obligor portfolios. Existing probability distributions with specified parameters are then used to approximate the loss distributions obtained. Using such parameters of the existing probability distributions, we obtain the risk quantities associated with the loan portfolio including Expected and Unexpected losses. We realized that depending on the confidence interval for which we measure the Unexpected Loss, Stress Losses are needed to account for the total loss of the portfolio.
\end{abstract}

Keywords: Economic Capital, Expected Loss, Unexpected Loss, Obligor, Loss Given Default, Exposure at Default, Stress Loss

\section{Introduction}

In the last two decades, credit risk management has become a topic of paramount importance in finance. Its importance became greatly significant, when in 2007 Lehman Brothers, one of the biggest investment banks in the US, collapsed after failing to honour its obligations. The collapse triggered a domino effect that led to several corporate failures leading to what became known as the credit crunch. If one considers the level of corporate debt, sovereign debt, retail loans, debt securitization vehicles and instruments that suffered during this period then the extent of the credit market and its effect on corporate and most national economies is overwhelming. Although banks in developing countries were not directly hit by the huge losses that characterized the European and American banks during the period, it is essential that their financial institutions develop robust credit risk management models as it continues to expose its businesses further in the international market. The dramatic growth in the credit market in developing countries especially in the last decade provides the drive and need for development and study of a wealth of new credit models.

Recent advances in credit risk models have been reflected in several reforms proposed by the Basel committee on banking supervision. Under the Basel proposal, banks can determine their own estimates of some of the components of risk measure: Probability of Default (PD), Loss Given Default (LGD), Exposure at Default (EAD) and Maturity (M). The goal of these regulations is to define risk weights by determining cut-off points between and within areas of Expected Loss and Unexpected Loss where regulatory capital is to be held, in the event of a default. Such determination of risk measures depends on the level of sophistication of the bank's credit models. These measures include the Standardized Approach, the Internal Ratings Based Approach (Foundation) and the Advanced Internal Rating Based Approach. Currently, most central banks in developing countries continue to use the Standardized Approach which simply specify the minimum capital requirements as a risk weight percentage (usually $8-10 \%$ of debt), to be held as capital [1]. Such models in banking supervision are not robust and sophisticated enough to withstand similar catastrophic losses such as which occurred in Europe and America. It is therefore essential that more advanced credit models are used to determine regulatory capital especially in Africa.

The seminal paper on credit risk modeling is Merton (1974). In Merton's model, the value of the total assets of a firm is modeled by a geometric Brownian motion. The firm defaults if its assets fall below the (fixed) level of its liabilities at a pre specified time horizon. An option pricing approach can then be used to value the firm's equity as a call option on its assets with strike price equal to the level 
of its liabilities [2]. The idea of linking a firm's default behaviour with the value of its assets is intuitively appealing, and has spawned the broad class of models referred to as structural models. The common feature of all of these models is the assumption that the firm's credit quality is determined by its capital structure and the values of its assets and liabilities. Joint default behaviour can then be introduced by linking the values of the assets and liabilities to macroeconomic factors. Examples of this approach include the CreditMetrics and Moody's-KMV models popular in industry [3].

In factor models, the price of a credit sensitive instrument is driven by the values of a set of fundamental random variables (common to all securities) as well as an idiosyncratic factor. The key property is the conditional independence of credit losses, given the values of the fundamental factors. Often, one-factor models admit a decomposition of the portfolio loss variable into a monotonic function of the factor and a residual. The former part of the decomposition is called systematic risk whereas the latter part is called specific or idiosyncratic risk. In this paper we will assume that the random variable $X$ is a macroeconomic factor affecting all defaults, and there exist an idiosyncratic factor $\mathcal{E}$ independent of $X$, affecting the industry within which the obligor operates [3].

Our approach in this study begins by outlining the risk components of a credit risk instrument of a loan portfolio which includes Expected Loss, Unexpected Loss, Loss Given Default, Exposure at Default and Maturity. As the number of obligors in a portfolio increases, the portfolio loss is then driven by the joint default behavior of the obligors. If all obligors default independently and the Loss Given Default instruments are independent, then the Central Limit Theorem implies that portfolio losses will tend to be normally distributed. However, in most cases this is not so as the obligor defaults do not occur independently. Default correlation, the tendency of defaults to occur together, can come from the fact that obligors may be drawn from same or similar industries, or affected by the overall health of the economy. Defaults can also be related due to contagion effect from direct ties between firms. This implies that obligor defaults are not independent. For these reasons, real portfolio losses tend to exhibit skewness and fat tails [3].

The joint probability of default is achieved by determining the asset value correlation of obligors. As true asset returns of individual obligors are not directly observable, equity prices are used as a proxy for asset returns to determine asset value correlation of obligors. Monte Carlo simulation, a probability simulation technique, is employed to understand the impact or how likely the resulting outcomes or default behaviour is dependent on the macroeconomic factors of systematic and idiosyncratic risk. Monte Carlo simulation is widely employed in finance. The most common use of Monte Carlo simulations in finance is when we need to calculate an expected value of a function $f(x)$ given a specified distribution density [4]. Phelim
(1977) developed a Monte Carlo simulation method for solving option valuation problems. The method simulates the process generating the returns on the underlying asset and invokes the risk neutrality assumption to derive the value of the option [5]. Recently, Monte Carlo simulation approach to generate loss distributions has also become popular in operational risk models. Enrique Navarrate developed operational risk quantification using Monte Carlo simulation [6]. A more detailed approach to credit risk using Monte Carlo simulation was outlined as in [7]. "For an extensive discussion of credit risk modeling see as outlined in [8].

In this paper, we employ Monte Carlo simulation by generating scenarios for the portfolio loss. This is achieved by simulating the common macroeconomic factor $X$ and the idiosyncratic factor $\mathcal{E}_{i}$. This procedure is repeated a large number of times to produce a sample from the true portfolio distribution. The credit risk measures of the distribution are then determined by methods of approximation using probability distributions. Although this procedure is computationally intensive (for example, in a particular scenario for a portfolio of size hundred there are 27,204,000 simulations), it can be applied to portfolio of any size. Thus, we begin with a portfolio of size two, extend it to ten and then to a portfolio of size hundred.

After obtaining frequency of loss using Monte Carlo simulation, we do not know the exact probability distribution followed by the loss distribution. To obtain the corresponding probability distribution, we employ analytical approximation method to determine the nature of distribution followed by the loss distribution. Methods of Approximation using a probability distribution have been successfully used in finance and engineering to determine solutions to analytic problems that do not have closed form solutions. It has many applications in risk analysis, quality control and cost scheduling. In finance, Giovanni Adesi provided a simple, analytic approximations method for pricing exchange-traded American call and put options written on commodities and commodity futures contracts [9]. The reasons for fitting a distribution to a set of data include the desire for objectivity, the need for automating the data analysis, and interest in the values of the distribution parameters [10].

One problem of analyzing data through the process of simulation and fitting a statistical distribution is that many other classical distribution functions could fit the sample and consequently, goodness-of-fit tests are needed to be performed on the constructed probability distribution functions [11]. However, recent developments in computer software offer programs that automatically assess the goodness-of-fit and provide the best distribution for a given data.

\section{Main Body}

We begin by outlining the building blocks of credit risk modeling and develop a simple framework for a portfolio 
of two assets. We will first use these components to generate loss distribution from which we will calculate the risk quantities for a two obligor portfolio and then extend the framework to a portfolio of 10 or more obligors.

\subsection{Components of Credit Risk Models}

We begin by looking at the various components of credit risk models, define these components and outline their mathematical contributions to the framework.

\subsubsection{Default}

There exist various definitions of default. Throughout the text we shall refer to default as failure to pay promptly Interest or principal on a loan agreement when due i.e. payment default. Basically, there are two methods of measuring losses due to credit risk: mark-to-market and default methods. The mark-to-market paradigm recognizes losses when the credit quality of the obligor (also referred to as debtor), deteriorates i.e. migrates to a lower credit rating. Such losses are not paid out, but only recognized when the portfolio of the bank is marked-to-market. Credit migration is the approach used by JP Morgan Chase Bank [12].

On the other hand, the default method recognizes losses only when they are realized in the form of default. Given that an obligor defaults, the loan provider or the obligee suffers a loss referred to as Loss Given default. Mathematically, the default method is a special case of the mark-to-market method (considering only two rating classes-default or survive). However, from a risk management view the two approaches are quite distinct. Throughout the text we shall focus on defaults only and ignore the credit risk related to credit migration. That is, we shall ignore the probability that the obligor would move from one credit quality to another including default within a given time horizon.

\subsubsection{Probability of default (PD)}

This indicates the degree of likelihood or the probability that promised payments such as interest and coupon payments and principal repayments will not be paid by the obligor. The assignment of a default probability to every customer in a credit portfolio is far from an easy task. There are essentially two approaches to this assignment:

\section{- Calibration of default probabilities from market data}

The most famous representation of this type is the concept of Expected Default Frequencies (EDF) developed by KMV Corporation. This method for calibrating default probabilities from market data is based on credit spreads of traded products bearing credit risk, e.g., corporate bonds and credit derivatives (swaps, etc.)

\section{- Calibration of default probabilities from ratings}

Basically, ratings describe the creditworthiness of customers. Ratings are assigned to customers either by external rating agencies like Moody' Investors Services, Standard \& Poor (S\&P) or FITCH, or by a bank internal rating methodologies. Quantitative as well as qualitative information is used to evaluate the client. In practice, the procedure is more often based on the judgment and experience of the rating analyst than on pure mathematical procedures with strict defined outcome. In ratings, many drivers of the considered firm's economic future are considered. These include future earnings and cash flows, debt, short and long term liabilities [5].

\subsubsection{Exposure at Default (EAD)}

Exposure at Default (EAD) estimates the amount that the obligor owes in case of default. EAD actually specifies the exposure a bank does have to its borrowers. For example, if a bank loans a $£ 1000$ to an obligor, then the bank's Exposure at Default is $£ 1000$. In general, the exposure consists of two major parts; the outstandings and commitments. The outstandings refer to the portion of the exposure already drawn by the obligor. In case of borrower's default, the bank is exposed to the total amount of the outstandings. The commitments can be divided into two portions, drawn and un-drawn, in the time of default. EAD can be defined as:

$$
E A D=\text { Outstandings }+\gamma \text { Commitments }
$$

Where $\gamma$ is the expected portion of the commitment likely to be drawn prior to default.

\subsubsection{Loss Given Default (LGD)}

The Loss Given Default (LGD) represent an estimate of the portion of the exposure-at-default that will not be recovered as a result of a default event, i.e., the LGD quantifies the portion of loss the lending entity will really suffer in case of default. The estimation of loss quotes is somehow complicated because recovery rates depend on many driving factors, for example on the quality of the collateral (securities, mortgages, guarantees, etc.) and on the "seniority" of the lenders claim on the borrower's assets Loss Given Default is thus considered as a random variable describing the severity of the loss of a facility type in case of default. LGD thus refers to the expectation of the severity of loss

$$
L G D=\text { Expected }[\text { Severity }]
$$

Most lending institutions depend on rating agencies as a source for data of defaulted bonds.

\subsubsection{Expected Loss $(E L)$}

Expected Loss (EL) gives an indication of the portfolio loss that we can expect to occur over the coming year. The Expected Loss of a transaction is an insurance or loss reserve to cover losses that a lending institution expects from historical default experience. In a capital charge requirement of a loan portfolio, the EL is provided for by pricing and provisions. As in probability theory, the attribute "expected" always refers to an expectation or mean value, and this is the case in credit risk. In assessing expected loss of a loan, a customer is assigned a Probability of Default (PD), a Loss Given Default (LGD) and an Exposure at Default (EAD).

A loss of any obligor is then defined by a loss variable 


$$
\text { Expected Loss }=P D \times L G D \times E A D
$$

Since the expected loss is not predictable to a certain degree we should mention that underlying our model is some probability space $(\Omega, F, \mathrm{P})$ where $\Omega$ is a sample space of a set of outcomes. $F$ is a collection of subset of $\Omega$ that form a $\sigma$ - field and $\mathrm{P}$ is a probability measure. The elements of $F$ are measurable events of the model and by intuition it makes sense to claim that the event of default should be measurable. For obtaining the representation above we need some assumptions that EAD and LGD are constant values. This is not necessarily the case under all circumstances. There are various situations in which for example EAD has to be modeled as a random variable. In such cases the EL is still given by Equation 1.3 if one can assume that the exposure, the LGD and the PD are independent and EAD and LGD are the expectations of some underlying random variable.

But whether the constituents of equation 1.3 are independent or not the basic concept of EL is still the same and for reasons of simplicity our convention will be that EAD is always deterministic (non-random) quantity whereas LGD will be considered as a random variable. Equation 1.3 is used to calculate the EL of a single loan. The portfolio EL is simply the sum of the ELs of the loans in the portfolio [7]

Example 1.

We shall look at the Expected Loss of two obligors; obligor 1 and obligor 2 that owe us 1000 and 2000 pounds respectively. This means our EAD is $£ 1000$ and $£ 2000$ for obligor 1 and obligor 2 respectively. Obligor 1 has a PD on its loan of $1 \%$, while obligor 2 has a PD of $2 \%$. The LGD for both loans is $50 \%$.

The Expected Loss of the loan for obligor 1 $=1 \% * 50 \% * 1000=0.01 * 0.5 * 1000=£ 5$

The Expected Loss of the loan for obligor 2 $=2 \% * 50 \% * 1000=0.02 * 0.5 * 2000=£ 20$

The Expected loss of the portfolio is therefore $=5+20=£ 25$

\subsubsection{Unexpected Loss}

We now look at the key components of credit risk modeling, starting with the standard deviation of loss. At the beginning, we introduced Expected Loss (EL) and pointed out that the EL of a transaction is an insurance or loss reserve to cover losses that a lending institution expects from historical default experience. But holding capital against expected losses is not enough. In fact, the lending institution should in addition to the expected loss reserve, also save money to cover unexpected losses exceeding the average experienced losses from past history. This arises because most of the time actual losses are not equal to the EL. We therefore need a measure of the deviation of actual losses around their expected levels. The standard deviation of loss measures this credit risk of transaction, typically called the Unexpected Loss (UL) [7].

\subsubsection{Unexpected Loss of a Single Credit Risk Transaction}

The unexpected loss of a credit risk transaction is a function of the PD, LGD, and EAD and their variances. PD, LGD and EAD are independent random variables. The unexpected loss is given in Equation 1.4

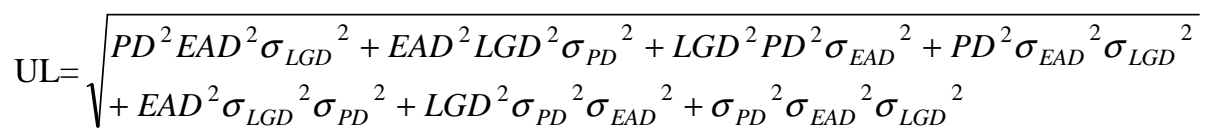

All the functions are independent and we will assume that the probability of default has a Bernoulli distribution, so that we can substitute $\sigma_{P D}^{2}$ by $\left(P D-P D^{2}\right)$. The Loss Given Default has a $\beta$ eta distribution, which allows us to replace $\sigma^{2}{ }_{L G D}$ by $\mathrm{LGD}^{*}(1-\mathrm{LGD}) / 4$, and $\mathrm{EAD}$ is assumed to be deterministic, so that $\sigma_{E A D}^{2}=0$. This leads to Equation 1.5.

$$
\text { Unexpected Loss }=E A D * \sqrt{\left[L G D^{2} * P D *(1-P D)+P D * L G D *(1-L G D) / 4\right]}
$$

\subsubsection{Unexpected Loss of a Portfolio}

regions), the unexpected loss of the portfolio is given by

Due to diversification (we can spread our investment over various positions in different industry sectors and

$$
\text { Unexpected Loss of a Portfolio }=\sqrt{\sum_{i=1, \ldots, n} \sum_{i=1, \ldots, n} U L_{i} * U L_{j} * \rho_{i, j}},
$$

Where $\rho_{i, j}$ represents the default correlation between obligor $i$ and obligor $j$ in a portfolio of $n$ obligors. For a portfolio of two obligors, $n=2$, the unexpected loss of the two credit risk transaction is a function of the ULs of the transactions and their correlation and is given in Equation 1.7

$$
\text { Portfolio Unexpected Loss }=\sqrt{U L_{1}{ }^{2}+U L_{2}{ }^{2}+2 U L_{1} U L_{2} \rho_{1,2}}
$$


$\rho_{1,2}$ is the default correlation between obligor 1 and obligor 2. The default correlation gives an indication of the tendency of the two loans to default at the same point in time. The default correlation between obligor $i$ and obligor $j$ is determined by Equation 1.8.

$$
\rho_{i, j}=\frac{J P D-P D_{i} * P D_{j}}{\sqrt{P D_{i} *\left(1-P D_{i}\right)\left(1-P D_{j}\right)}}
$$

Where $J D P$ is the joint probability of default of obligor $i$ and $j$ ad $P D_{i}$ and $P D_{j}$ are the probability of default of obligor $i$ and $j$ respectively. The Joint Probability of Default is a function of the $P D$ 's of the obligors and their asset correlation.

$$
J D P=J D P\left(P D_{i}, P D_{j}, \text { asset } \text { correlation }_{i, j}\right)
$$

The Joint Probability of Default is established by determining the volume under the asset value distribution up to the default threshold of the two obligors. Mathematically, the $J D P$ is a double integral which is approximated by a Visual Basic program in Excel [7].

The Unexpected Loss determined in this procedure represents credit risk at one standard deviation of loss. This provides confidence level of around 90\% which is not sufficient to capture all the losses associated with the loan portfolio. For highly rated financial institutions with confidence level of $99.9 \%$, this additional loss, referred to as Stress Loss (SL) is highly significant. We would determine the Stress Loss associated with each portfolio after the simulation procedure outlined in 3.

\section{Simulation Procedure}

We will now use a Monte Carlo simulation procedure to generate frequency of loss of the portfolio by following the following steps:

1. Specify PD, LGD and EAD and R (systematic factor) for the portfolio.

2. Simulate changes in the state of the economy by generating random variables from 0 to 1 ;

Macroeconomic factor for scenario $i=$ NORMSINV (RAND ( ))

3. Simulate changes in the obligor specific risk $\varepsilon$ by generating random variables from 0 to 1 ;

Specific Factor for obligor $i=$ NORMSINV (RAND ( ))

4. Obtain asset return of each obligor given by:

Asset return obligor $i=$

$$
r_{i}=\left(\sqrt{R^{2}}\right) * Y+\left(\sqrt{1-R^{2}}\right) * \varepsilon
$$

where $Y$ is the state of economy and $\varepsilon_{i}$ is the obligor specific risk and $Y$ and $\mathcal{E}$ are obtained from steps 2 and 3 respectively and $R$ is as specified in step 1 .

5. Set Default Point $d_{i}$, where $d_{i}=\operatorname{NORMSINV}(P D)$.
If $r_{i}<d_{i}$ then it follows that obligor's asset value has dropped below the default threshold and hence obligor defaults, otherwise the obligor survives [7].

By repeating the simulation of defaults many times, we will obtain frequency of losses from which we obtain histograms of the loss frequencies. We shall initially perform the Monte Carlo simulation for a portfolio of two obligors and then extend it to a portfolio of 10 and 100 obligors. The results of the simulation for a two obligor portfolio are shown in Figure 1. Similar simulation procedures are obtained for 10 and 100 obligor portfolios.

\subsection{Analytical Approximation Methods}

We have so far used Monte Carlo simulation technique to obtain an empirical loss distribution of an underlying portfolio consisting of two and ten and hundred obligors. However, we do not know the exact probability distribution followed by the frequency loss distributions. To obtain the corresponding probability distribution we shall use an analytical approximation method to fit a probability distribution function to the loss frequency. Typically, the analytical approximation method maps an actual portfolio with unknown loss distribution to an equivalent portfolio with known loss distribution. The loss distribution of the equivalent portfolio is then taken as a substitute for the "true" loss distribution of the original portfolio. In practice this is often achieved by choosing a family of distributions characterized by its first and second moments showing the typical shape of loss distribution (i.e., right-skewed with fat tails). We can then choose from the parameterized family of loss distributions, the distribution best matching the original portfolio with respect to first and second moments [1]. Thus, the analytical approximation method works by approximating the loss distribution of the original portfolio by a known distribution and matching the first and second moments of the original portfolio to the parameters of the known portfolio. Thus, suppose we match our loss distribution (unknown) to say beta distribution (known), then basically we are looking for a random variable $X \sim \beta(\alpha, \beta)$, representing the percentage portfolio loss such that the parameters $\alpha$ and $\beta$ solve the first and second moments of the beta distribution.

The probability density function of the beta distribution is given as:

$$
\beta_{a, b}(X)=\frac{\Gamma(a+b)}{\Gamma(a) \Gamma(b)} X^{a-1}(1-X)^{b-1}
$$

with first moment

$$
E[X]=\frac{\alpha}{\alpha+\beta}
$$

and second moment

$$
V[X]=\frac{\alpha \beta}{(\alpha+\beta)^{2}(\alpha+\beta+1)}
$$


The analytical approximation thus takes the random variable $X$ as a proxy for the unknown loss distribution of the portfolio we started with. Following this assumption, the risk quantities of the original portfolio can be approximated by the respective quantiles of the random variable $X$. For example, the quantiles of the loss distribution of our portfolio can be calculated as quantiles of the beta distribution [13]. Thus, the true loss distribution is substituted by a closed-form, analytical and a wellknown distribution. This is very useful for computational purposes. We shall now perform Monte Carlo simulation for Two (2), Ten (10) and Hundred (100) obligor portfolios.

\section{Results and Discussions}

\subsection{2-Obligor Portfolio Simulation}

For the two-obligor portfolio we generate a scenario by setting the following risk measures:

$P D=5 \%$ (Set by bank using historical default rates)

$E A D=£ 3,000$ ( $£ 1000$ to obligor $1, £ 2000$ to obligor 2 )

$L G D=60 \%$ (obtained from historical average of LGDs)

$\mathrm{M}=$ Maturity $=1$ year

$\rho=$ Joint Default Probability of portfolio $=0.5$

The simulation result is summarized in Table 1 .

Table 1. Simulation Results for 2-Obligor Portfolio.

\begin{tabular}{|c|c|c|c|c|c|c|c|c|}
\hline Simulation & Macro factor & $\begin{array}{c}\text { Specific factor } \\
\text { Obligor } 1\end{array}$ & $\begin{array}{c}\text { Specific factor } \\
\text { Obligor } 2 \\
\end{array}$ & $\begin{array}{c}\text { Return } \\
\text { Obligor } 1 \\
\end{array}$ & $\begin{array}{c}\text { Return } \\
\text { Obligor } 2 \\
\end{array}$ & $\begin{array}{c}\text { Default Point } \\
\text { Obligor } 1 \\
-2.3263 \\
\text { Default } \\
\text { Obligor } 1 \\
\end{array}$ & $\begin{array}{c}\text { Default Point } \\
\text { Obligor } 1 \\
-2.3263 \\
\text { Default } \\
\text { Obligor } 2 \\
\end{array}$ & $\begin{array}{c}\text { Portfolio } \\
\text { Loss }\end{array}$ \\
\hline 1 & -1.6413 & 0.3537 & -1.6019 & -1.3099 & -2.1336 & 0 & 0 & 0 \\
\hline 2 & 0.6115 & -1.9249 & 0.6132 & -0.3139 & 0.8013 & 0 & 0 & 0 \\
\hline 3 & -1.0385 & -0.5481 & 0.4594 & -1.1740 & -0.7795 & 0 & 0 & 0 \\
\hline 4 & 1.7269 & 0.3124 & -0.5896 & 1.6843 & 1.3638 & 0 & 0 & 0 \\
\hline 5 & -0.1714 & -0.0585 & 0.1452 & -0.1795 & -0.1018 & 0 & 0 & 0 \\
\hline 6 & 0.2654 & 1.6402 & -0.2968 & 0.9709 & 0.1297 & 0 & 0 & 0 \\
\hline 7 & -1.7894 & 0.7774 & 0.5050 & -1.2528 & -1.4542 & 0 & 0 & 0 \\
\hline 8 & -1.1192 & 0.4465 & -1.5877 & -0.8013 & -1.6467 & 0 & 0 & 0 \\
\hline 9 & -0.2123 & -0.2061 & -0.1971 & -0.2821 & -0.2721 & 0 & 0 & 0 \\
\hline 10 & -0.4145 & 1.3266 & -0.6000 & 0.2225 & -0.6145 & 0 & 0 & 0 \\
\hline 11 & -0.9587 & 2.5191 & 2.2991 & 0.2691 & 0.0066 & 0 & 0 & 0 \\
\hline 12 & 0.7650 & 1.9007 & 0.1621 & 1.5342 & 0.7680 & 0 & 0 & 0 \\
\hline 13 & 0.8657 & 1.4769 & 0.7657 & 1.4348 & 1.0947 & 0 & 0 & 0 \\
\hline
\end{tabular}

The loss frequency obtained is summarized in the Table 2 and the resulting histogram is shown in Figure 1.

Table 2. Frequency Distribution of 2-Obligor Portfolio.

\begin{tabular}{cccc}
\hline Losses & Frequency & $\begin{array}{c}\text { Percent of } \\
\text { Frequency }\end{array}$ & $\begin{array}{c}\text { Cumulative } \\
\text { Frequency }\end{array}$ \\
$£ 0.00$ & 1955 & $97.98 \%$ & $97.98 \%$ \\
$£ 100.00$ & 41 & $2.0137 \%$ & $100.00 \%$ \\
$£ 200.00$ & 0 & 0 & $100.00 \%$ \\
$£ 300.00$ & 0 & 0 & $100.00 \%$ \\
$£ 400.00$ & 0 & 0 & $100.00 \%$ \\
$£ 500.00$ & 0 & 0 & $100.00 \%$ \\
$£ 600.00$ & 0 & 0 & $100.00 \%$ \\
$£ 700.00$ & 0 & 0 & $100.00 \%$ \\
$£ 800.00$ & 0 & 0 & $100.00 \%$ \\
$£ 900.00$ & 0 & 0 & $100.00 \%$ \\
$£ 1,000.00$ & 0 & 0 & $100.00 \%$ \\
\hline
\end{tabular}

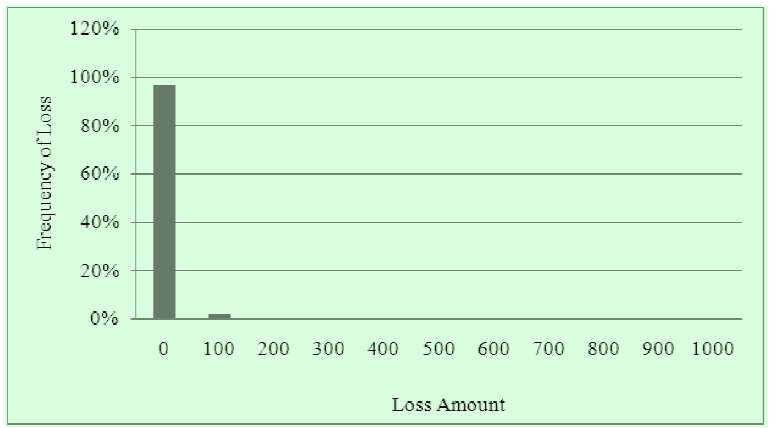

Figure 1. Frequency Distribution of 2-Obligor Portfolio.

The probability distribution function that best fit the 2obligor portfolio is the bounded gamma distribution with parameters $\alpha=2.2727$ and $\theta=220$. This gamma distribution is completely characterized by two parameters, $\alpha$ and $\theta$. These quantities are linked as follows:

$$
\begin{gathered}
\mu=\alpha \theta \\
\sigma=\alpha \theta^{2}
\end{gathered}
$$

The probability density function of a gamma distribution is: 


$$
P(x)=\frac{1}{\Gamma(\alpha) \theta^{\alpha}} \int x^{\alpha-1} \exp (-x / \theta) d x
$$

Where $x$ is the distribution variable, and $\Gamma$ is the standard gamma function evaluated at the relevant parameters and defined by the function

$$
\Gamma(x)=\int_{0}^{\infty} u^{x-1} \exp (-x) d u .
$$

By using gamma function to approximate the distribution of losses it follows that there exist a random variable $x \sim g(\alpha, \theta)$, representing the percentage portfolio loss such that the parameters $\alpha$ and $\theta$ solve the first and second moments of the gamma distribution. The total portfolio loss is simply the value of $x$ when $P(x)=$ Confidence interval (chosen to comply with bank's risk appetite). Thus, suppose we set the confidence interval at $95 \%$, then the total loss of the portfolio is the value of $x$ such that:

$$
0.95=\frac{1}{\Gamma(\alpha) \theta^{\alpha}} \int x^{\alpha-1} \exp (-x / \theta) d x
$$

Several other distributions can be fitted to the mean and standard deviation of loss rate data but the gamma distribution provides the best fit for all the three portfolios. The gamma distribution of the 2-Obligor portfolio is shown in Figure 2.

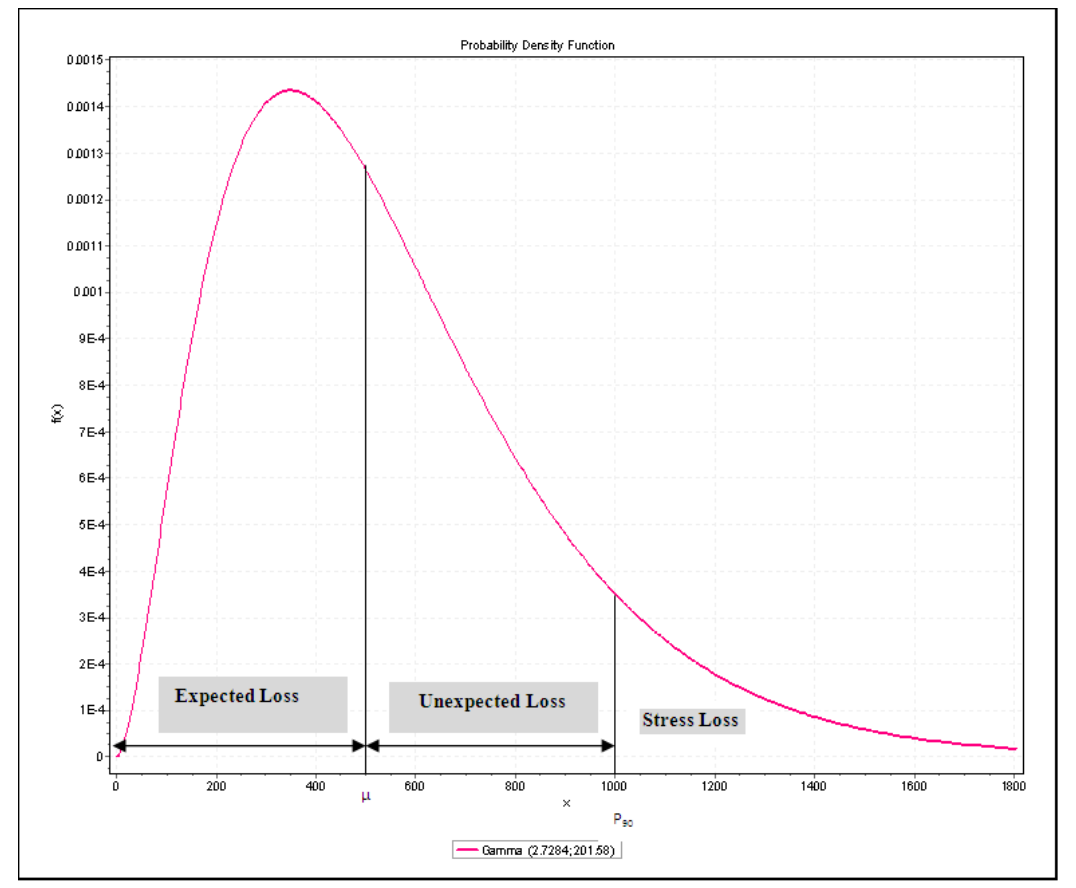

Figure 2. Graph of Gamma Distribution for 2-Obligor Portfolio.

The data statistics and percentile distribution of losses obtained from the gamma distribution are given in Table 3

and Table 4 respectively.

Table 3. Data Statistics of 2-Obligor Portfolio.

\begin{tabular}{|c|c|c|c|c|c|c|c|c|c|}
\hline Percentile & Min & $5 \%$ & $10 \%$ & $25 \%(\mathrm{QI})$ & $50 \%$ (Median) & $75 \%(Q 3)$ & $90 \%$ & $95 \%$ & $\operatorname{Max}$ \\
\hline Value(£) & 0 & 0 & 20 & 200 & 500 & 800 & 980 & 1000 & 1000 \\
\hline
\end{tabular}

\begin{tabular}{ccccccccc}
\hline Statistic & Range & Mean & Variance & $\begin{array}{c}\text { Standard } \\
\text { Deviation }\end{array}$ & $\begin{array}{c}\text { Coefficient } \\
\text { Of Variation }\end{array}$ & Standard Error & Skewness & $\begin{array}{c}\text { Excess } \\
\text { Kurtosis }\end{array}$ \\
\hline Value $(\mathfrak{k})$ & 1000 & 500 & $1.1000 \mathrm{E}+5$ & 331.66 & 0.66332 & 100 & 0 & -1.2 \\
\hline
\end{tabular}

Table 4. Percentile Distribution of 2-Obligor Portfolio.

From Table 3:

Mean $=500$

Standard deviation $=331.66$

Hence

Expected Loss of portfolio $=£ 500$

Unexpected Loss of portfolio $=£ 331.66$

The total loss of the portfolio is $£ 1000$. Thus by our convention;
Stress Loss $=$ Total Loss - Expected Loss - Unexpected Loss

Stress Loss $=£ 1000-£ 831.66=£ 168.34$

For this portfolio there is no loss beyond the $95^{\text {th }}$ percentile, that is, $95^{\text {th }}$ percentile coincides with the maximum loss of the portfolio. Thus, in this portfolio setting a risk tolerance of $95 \%$ will be sufficient to total loss of the portfolio. 


\subsection{0-Obligor Portfolio Simulation}

For the 10-Obligor portfolio we generate a scenario by setting the following risk measures:

$P D=5 \%$ (Set by bank using historical default rates)

$E A D=£ 20,150$

$L G D=60 \%$ (Obtained from historical average of LGDs)

$\mathrm{M}=$ Maturity $=1$ year

$\rho=$ Joint Default Probability of portfolio $=0.5$

The loss frequencies are shown in Table 5 and the corresponding histogram generated is shown in Figure 3.

The probability distribution that fit the data in the 10Obligor portfolio is the bounded Gamma distribution with



Figure 3. Frequency Distribution of 10-Obligor Portfolio. parameters $\alpha=2.2727$ and $\theta=220$. This is shown in Figure 4 .

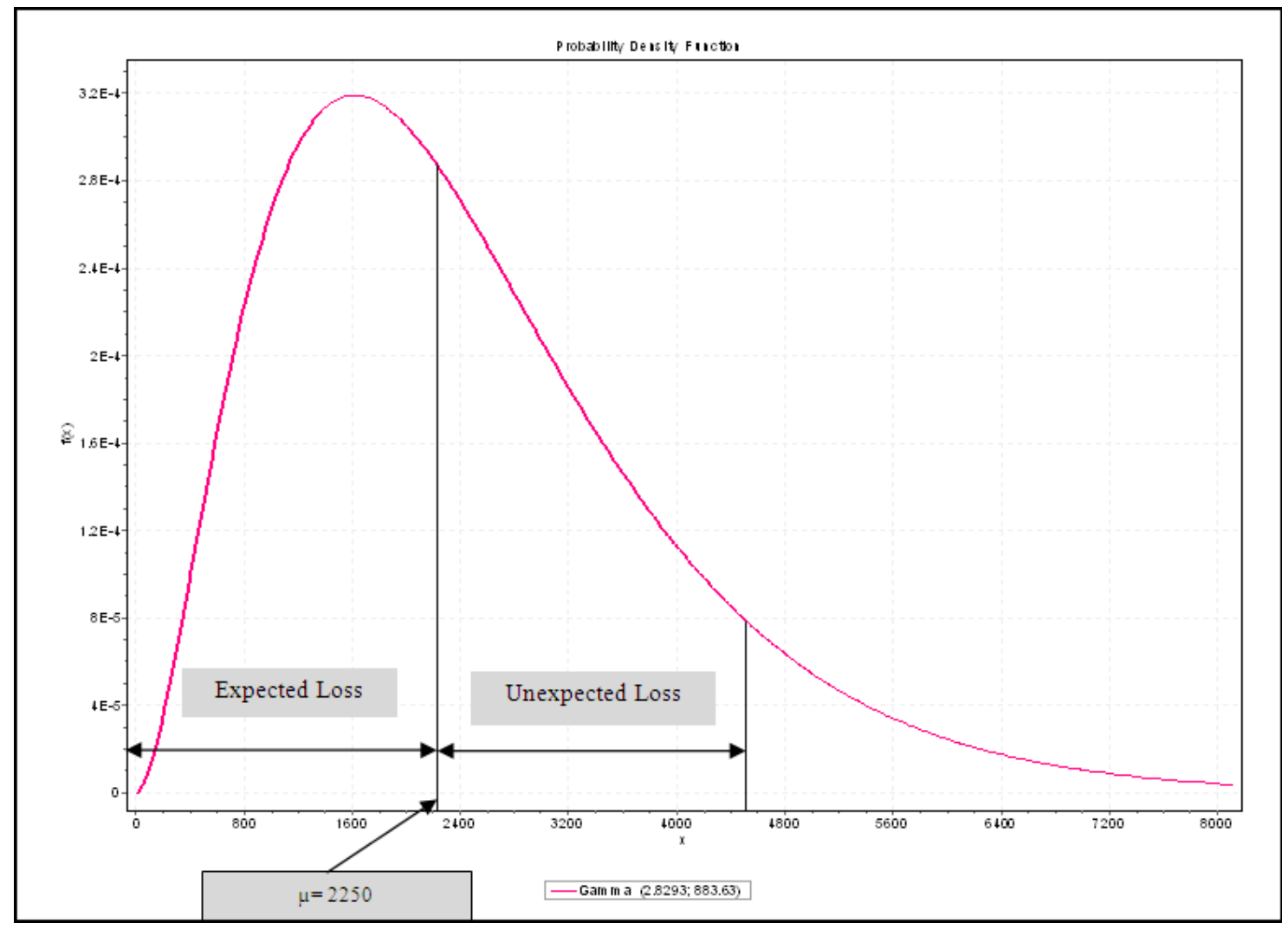

Figure 4. Graph of Gamma distribution for 10-Obligor Portfolio.

The data statistics and percentile distribution of loss obtained from the gamma distribution are given in Table 5

and Table 6 respectively.

Table 5. Data Statistics of 10-Obligor Portfolio.

\begin{tabular}{ccccccccc}
\hline Statistic & Range & Mean & Variance & $\begin{array}{c}\text { Standard } \\
\text { Deviation }\end{array}$ & $\begin{array}{c}\text { Coefficient of } \\
\text { Variation }\end{array}$ & $\begin{array}{c}\text { Standard } \\
\text { Error }\end{array}$ & Skewness & $\begin{array}{c}\text { Excess } \\
\text { Kurtosis }\end{array}$ \\
\hline Value( $(\mathfrak{)})$ & 4500 & 2250 & $2.2917 \mathrm{E}+6$ & 1513.8 & 0.67281 & 478 & 0 & -1.2 \\
\hline
\end{tabular}

Table 6. Percentile Distribution of 10-Obligor Portfolio.

\begin{tabular}{cccccccccc}
\hline Percentile & Min & $\mathbf{5 \%}$ & $\mathbf{1 0 \%}$ & $\mathbf{2 5 \%}(\mathrm{QI})$ & $\mathbf{5 0 \%}($ Median) & $\mathbf{7 5 \%}(\mathbf{Q 3})$ & $\mathbf{9 0 \%}$ & $\mathbf{9 5 \%}$ & Max \\
\hline Value $(\mathfrak{f})$ & 0 & 0 & 50 & 875 & 2250 & 3625 & 4450 & 4500 & 4500 \\
\hline
\end{tabular}

From Table 5:

Mean $=2,250$
Standard deviation $=1,513.8$

Hence 
Expected Loss of the portfolio $=£ 2,250$

Unexpected Loss of the portfolio $=£ 1,513.80$

Stress Loss $=£ 4500-£ 3763.80=£ 736.20$

In this portfolio, there is no loss beyond the $95^{\text {th }}$ percentile as the $95^{\text {th }}$ percentile coincides with the maximum value of the losses which is $£ 4500$. In this portfolio setting a risk tolerance of $95 \%$ will be sufficient to cover the total loss of the portfolio.

\subsection{Hundred (100) - Obligor Portfolio Simulation}

The simulation procedure is extended to a portfolio containing hundred obligors as obtained in real life banking operation. For the 100-obligor portfolio we generate a scenario by setting the following risk measures

Asset value correlation is set at 0.5 .

$P D=5 \%$ (Set by bank using historical default rates) $E A D=£ 10,000,000,000=$ sum of loans to the 100 obligors $L G D=60 \%$ (obtained from historical average of $L G D s$ ) $M=1$ year $\rho=$ Joint Default Probability of portfolio $=0.5$

The loss frequency generated from the simulations and the corresponding histogram is shown in Table 7 and Figure 5 respectively.

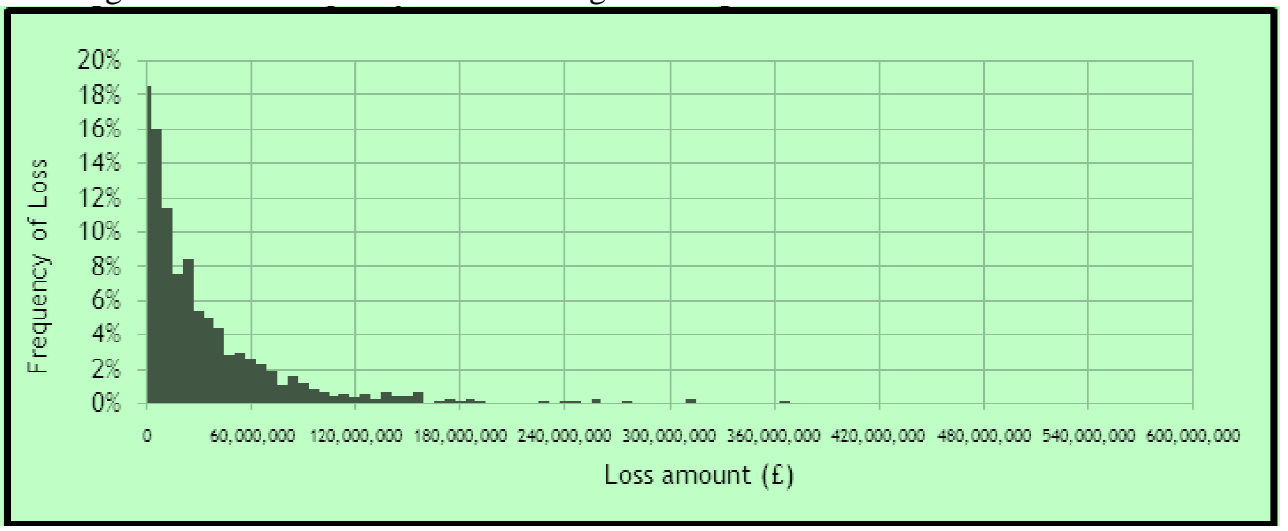

Figure 5. Frequency Distribution of 100-Obligor Portfolio.

The probability distribution function that best describe the data in the 100-Obligor portfolio is the bounded gamma distribution with parameters $\alpha=1.2632$ and $\theta=2.9367 \mathrm{E}+7$. This is shown in Figure 6.

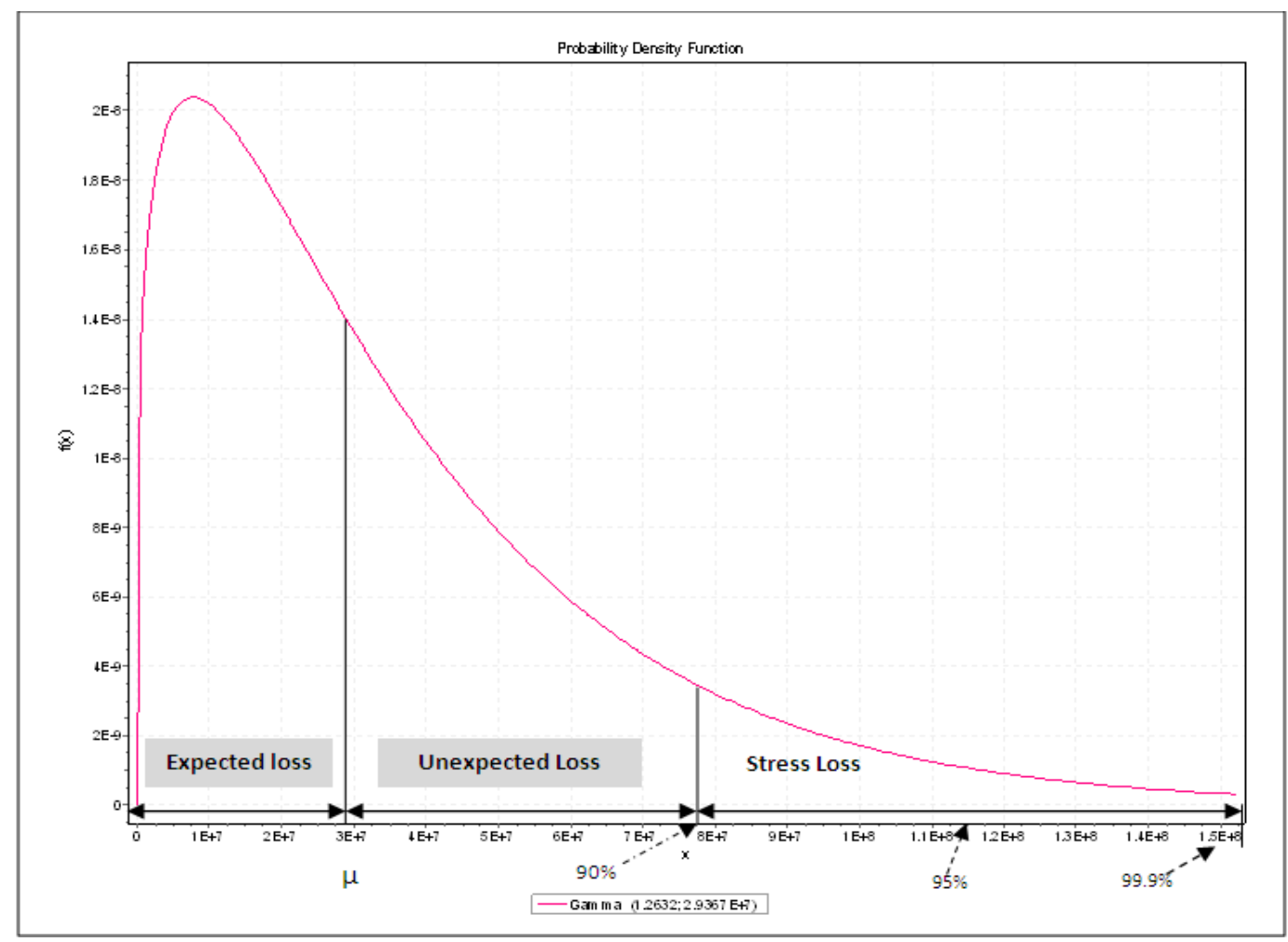

Figure 6. Graph of Gamma Distribution for 100-Obligor Portfolio.

The data statistics and percentile distribution of loss obtained from the gamma distribution are given in Table 
7 and Table 8 respectively.

Table 7. Data Statistics of 100-Obligor Portfolio.

\begin{tabular}{|c|c|c|c|c|c|c|c|c|}
\hline Statistic & Range & Mean & Variance & $\begin{array}{l}\text { Standard } \\
\text { Deviation } \\
\end{array}$ & $\begin{array}{c}\text { Coefficient of } \\
\text { Variation } \\
\end{array}$ & $\begin{array}{c}\text { Standard } \\
\text { Error }\end{array}$ & Skewness & $\begin{array}{c}\text { Excess } \\
\text { Kurtosis } \\
\end{array}$ \\
\hline Value(f) & $2.5800 \mathrm{E}+8$ & $2.8826 \mathrm{E}+7$ & $1.3693 \mathrm{E}+15$ & $3.7003 \mathrm{E}+7$ & 1.2837 & $1.1547 \mathrm{E}+6$ & 2.3151 & 6.8926 \\
\hline
\end{tabular}

Table 8. Percentile Distribution of 100-Obligor Portfolio.

\begin{tabular}{lccccccccc}
\hline Percentile & Min & $\mathbf{5 \%}$ & $\mathbf{1 0 \%}$ & $\mathbf{2 5 \%}(\mathbf{Q I})$ & $\mathbf{5 0 \%}($ Median) & $\mathbf{7 5 \%}(\mathbf{Q 3})$ & $\mathbf{9 0 \%}$ & $\mathbf{9 5 \%}$ & Max \\
\hline Value $(\mathfrak{f})$ & 0 & 0 & 0 & $6.0000 \mathrm{E}+6$ & $1.8000 \mathrm{E}+7$ & $3.6000 \mathrm{E}+7$ & $7.8000 \mathrm{E}+7$ & $1.0200 \mathrm{E}+8$ & $1.5800 \mathrm{E}+8$ \\
\hline
\end{tabular}

From Table 8:

Mean $=2.8800 \mathrm{E}+7$

Standard deviation $=3.7003 \mathrm{E}+7$

Hence Expected Loss of the portfolio $=£ 2.8800 \mathrm{E}+7$

Unexpected Loss of the portfolio $=£ 3.7003 \mathrm{E}+7$

In this portfolio, there are losses beyond the $95^{\text {th }}$ percentile as the $95^{\text {th }}$ percentile does not coincide with the maximum loss of the portfolio. The cumulative loss up to the $95^{\text {th }}$ percentile is $£ 1.02 \mathrm{E}+8$. The cumulative loss up to $99.9^{\text {th }}$ percentile is $£ 1.58 \mathrm{E}+8$. This means that a bank or an institution keeping such a portfolio whose risk tolerance is 95\% CI will keep a sum of $£ 102 \mathrm{~m}$ as Unexpected Capital. However, a bank with a high risk tolerance such as AAA bank, with risk tolerance of $99.9 \%$ CI will keep a sum of $£ 258 \mathrm{~m}$ as Unexpected Capital. For this portfolio, the Stress Loss is computed as:

Stress Loss=Total Loss - Expected Loss - Unexpected Loss

Stress Loss $=£ 1.5800 \mathrm{E}+8-£ 2.8800 \mathrm{E}+7-£ 3.7003 \mathrm{E}+7$

$$
=£ 92,197,000
$$

\section{Conclusions}

We have so far outlined and developed a model that can determine potential portfolio loss in excess of the UL. We have shown that based on your confidence level a bank can hold capital far in excess of the UL. It now lies with the bank's credit risk management team to determine whether to hold capital against losses in excess of the unexpected loss, beyond say $90^{\text {th }}$ percentile of the distribution. Usually, highly rated banks such as AAA banks would like to hold reserves to cover stress losses. However, banks with lower ratings will deem it too expensive to hold capital against such huge potential losses which has very low probability of occurrence. It must be emphasized here that although losses beyond the $90^{\text {th }}$ percentile are huge, they have very low probability of occurring. For example, from Figure 5, it can be observed that beyond the $90^{\text {th }}$ percentile there is a loss of around $£ 240,000,000$, but the probability of such loss occurring is about 0.01 . However, should such loss (catastrophic) arise, it could lead to the collapse of the institution. In a climate of high level of defaults, uncertainty and corporate bankruptcy, it will be prudent and risk sensible for a bank to keep capital to cover such losses. As we have seen, simulation methods are simple to implement and interpret. It is able to determine all the losses in a loan portfolio and percentiles can be determined at different confidence levels. In summary, the methods we have provided here will simplify the processes involved in the determination of portfolio risk.

\section{References}

[1] Martin, Hansen, Dr. Gary, van Vuuren and Mariarosa, Verde Basel II Correlation Values., An Empirical Analysis of EL, UL and the IRB Model, Credit Market Research Financial Institutions Special Report, Fitch Rating, 2008, pp3

[2] Merton, R. (1974): On the Pricing of Corporate Debt: The Risk Structure of Interest Rates," Journal of Finance, 29, 449-470.

[3] David Saunders, Costas Xiouros, Stavros A. Zenios, Credit risk optimization using factor models. Annals of Operations Research, (2007), pp.49-77

[4] Peter J"ackel, Monte Caro methods in finance Wiley Finance \& Sons Ltd. Chichester, England (2002), PP 1-6

[5] Phelim P. Boyle, Journal of Financial Economics, Volume 4, Issue 3, May 1977, Pages 323-338

[6] Enrique Navarrete, Practical Calculation of Expected and Unexpected Losses on Operational Risk by Simulation Methods, Banca \& Finanzas: Documentos de Trabajo, 2006 Vol. I, pp. 7-9

[7] Hoogbruin, Peter P, Journal of Global Association of Risk Professionals, (September/October 2006), pp. 34-39.

[8] Loffler, Gunter and Posch, Peter N. Credit Risk Modeling using Excel and VBA, Wiley Finance Series, John Wiley \& Sons, Ltd., New York, NY, USA, 2007.

[9] GIOVANNI BARONE-ADESI, Efficient Analytic Approximation of American Option Values, The Journal of Finance, Volume 42, Issue 2, 1987, pp 301 -320.

[10] John S. Ramberg, Pandu R. Tadikamalla, Edward J. Dudewicz, Edward F. Mykytka, A Probability Distribution and Its Uses in Fitting Data. American Statistical Association and American Society for Quality Technometrics, v ol.2 1, no. 2, may, 1979

[11] AbouRizk, S., Halpin, D., and Wilson, J. Fitting Beta Distributions Based on Sample Data Journal of Construction Engineering and Management Volume 120, Issue 2 (June 1994). Pp 288-289

[12] Bluhm, Ludger Overbeck and Wagner, C. An Introduction to Credit Risk Modeling, Christian Chapman \& Hall/CRC, London, UK, 2003. 
[13] Barreto, Humberto and Howland, Frank M. Introductory Econometrics, Cambridge University Press, Cambridge, UK, 2006; pp 215-235.

[14] Berenson, Mark L., Levine, David M. Basic Business Statistics, Prentice-Hall International inc New Jersey, NJ, USA, 1999; pp 45-75.
[15] David Vose, Risk Analysis a Quantitative Guide, John Wiley \& Sons Ltd., New York, NY, USA, 2003; pp 59

[16] Haigh, J. Probability Models, Springer Undergraduate Mathematical Series, Springer, New York, NY, USA, 2005, pp. 1-86 